\title{
DINÂMICAS URBANAS E PESQUISAS DO NÚCLEO DE ESTUDOS DA PAISAGEM NA ÁREA DE MANANCIAIS
}

\author{
URBAN DINAMICS AND RESERCHS OF THE CENTER OF \\ LANDSCAPE STUDIES IN THE WATER SUPLLIES AREA
}

Euler Sandeville Júnior

Arquiteto e Urbanista, Arte-Educador, Pós-graduado em Ecologia, Mestre e Doutor em Estruturas Ambientais Urbanas pela FAUUSP. Professor Livre-Docente do Departamento de Projeto da FAUUSP, Vice-coordenador da Área Paisagem e Ambiente do Programa de PósGraduação em Arquitetura e Urbanismo da USP, Coordenador do Laboratório Espaço Público e Direito à Cidade, FAUUSP.

e-mail: esandeville@gmail.com. URL: http://espiral.net.br

\section{Priscila Ikematsu}

Engenheira Ambiental, Pesquisadora do Instituto de Pesquisas Tecnológicas - IPT, Mestranda pela FAUUSP - Área Paisagem e Ambiente. Pesquisadora do Núcleo de Estudos da Paisagem. e-mail:pri_ike@yahoo.com.br

\section{Gabriella Roesler Radoll}

Arquiteta e Urbanista, Mestranda pela FAUUSP - Área Paisagem e Ambiente. Pesquisadora do Núcleo de Estudos da Paisagem.

e-mail: gabriella.radoll@gmail.com

\section{Simone Miketen}

Socióloga, Mestranda pelo PROCAM-USP - Conservação e Desenvolvimento Socioambiental - Pesquisadora do Núcleo de Estudos da Paisagem.

e-mail:simonemiketen@gmail.com

\section{RESUMO}

Este trabalho apresenta os estudos do Núcleo de Estudos da Paisagem (NEP) desenvolvidos nas áreas de importantes reservatórios de água utilizados para o abastecimento público: as represas Billings e Guarapiranga. Os trabalhos são realizados em diferentes escalas de análise e estão focados na necessidade de compreender os processos urbanos e ambientais, além de formas de participação social. Os métodos utilizados são bastante diversos, incluindo trabalhos de campo, mapeamentos temáticos, cartografia de atores, entrevistas e observação participante, a fim de discutir as transformações da paisagem na escala regional e conflitos decorrentes, correlacionando-as com as escalas locais no cotidiano da população. Os resultados de tais estudos reforçam a urgência de ações voltadas à melhoria da qualidade socioambiental e urbana dessa região, mas indicam a necessidade de ampliação da equipe para trabalhos colaborativos com grupos locais, considerando a complexidade e a escala espacial dos fenômenos urbanos e ambientais. Com isso, é possível trazer nova compreensão desses processos, bem como iluminar e problematizar aspectos que contribuam para a análise das implicações das políticas públicas e dos processos de construção do urbano, de seus contextos políticos, e esclarecer as atuais condições para uma efetiva participação da população no planejamento e gestão das áreas de mananciais intensamente urbanizados.

Palavras-chave: Paisagem, Planejamento da paisagem, Participação social, Mananciais 


\begin{abstract}
This paper presents the researchers developed at the Center for Landscape Study (NEP) focused on important water source areas for public supply - the Guarapiranga and Billings reservoirs. The studies regard different analysis scales and align with the necessity to comprehend the urban and environmental processes, besides the social participation. Diverse methods are used, including field work, thematic and stakeholders mapping, interviews and participant observation, in order to discuss the regional landscape changes and it's caused conflicts, correlating them with the local scales. The results of such researches reinforce the urgency of actions directed to the socioenvironmental and urban quality improvement on the area, the necessity to enlarge the team to collaborative works with local groups, considering the complexity and the scope of the urban and environmental phenomenon. Thereby, it's possible to bring new comprehension of the processes, as well as to illuminate and expound aspects which contributes to the analysis of public policies implications and of the urban construction processes, of its political contexts, and to clarify the actual conditions for effective popular participation on planning and management of urbanized water source areas for public supply.
\end{abstract}

Keywords: Landscape, Landscape planning, Social participation, Water source areas for public supply

\title{
APRESENTAÇÃO
}

Os estudos na região de mananciais dos reservatórios Billings e Guarapiranga, do Núcleo de Estudos da Paisagem (NEP), iniciaram-se com a participação no projeto de Políticas Públicas (FAPESP), coordenado pelo Programa de Pós-Graduação em Ciência Ambiental (PROCAM/USP). Realizado entre 2008 e 2010, nos municípios de Embu e Taboão da Serra, teve foco na Aprendizagem Social na gestão de recursos hídricos. Outras pesquisas foram a Iniciação Científica e o trabalho de graduação de Gabriella Roesler Radoll no município do Embu (2009-2010). A participação desde 2010 (em curso) no Convênio de Cooperação Técnico-Científica para elaboração do Plano de Manejo dos Parques da Compensação do Rodoanel Trecho Sul, coordenado pelo Departamento de Geografia da Faculdade de Filosofia, Letras e Ciências Humanas (FFLCH-USP) trouxe a possibilidade de organizar uma equipe de trabalho na área dos mananciais (participaram sob coordenação de Euler Sandeville os pesquisadores Gabriella R. Radoll, Larissa Nebesnyi, Rafael Siqueira, José Muñoz, Andréa Conard, Giovana Aiello, Simone Miketen e Henrique Pozos).

Dessas atividades resultaram as primeiras pesquisas de pós-graduação na zona sul do município de São Paulo com os mestrados de Simone Miketen (início em 2010, sobre as áreas rurais em processo de conversão agroecológica no contexto urbano), de Gabriella R. Radoll (início em 2011, sobre as potencialidades para a criação de sistema de espaços públicos de conservação e lazer), e de Priscila lkematsu (início em 2011, sobre os desafios e conflitos relacionados ao planejamento e gestão na Área de Proteção e Recuperação dos Mananciais da Bacia Hidrográfica do Guarapiranga (APRM-G). Alguns resultados iniciais podem ser acompanhados em Sandeville Jr. \& Radoll (2010) e lkematsu \& Sandeville Jr. (2011). A partir de 2012 inicia-se também o mestrado de Melissa Matsunaga, estudando as intervenções de requalificação urbana no núcleo Cantinho do Cév, localizado na bacia do Reservatório Billings.

Esse conjunto de trabalhos está permitindo gerar um fluxo de cooperação entre as pesquisas de modo a favorecer a compreensão dos processos da dinâmica da paisa- 
gem determinantes a cada escala. Com isso, é possível o aprofundamento da nossa percepção em relação à realidade extremamente complexa da área de mananciais da metrópole paulistana e a integração das visões de diferentes profissionais em uma mesma área de estudo. As pesquisas procuram relacionar os métodos de planejamento da paisagem com a compreensão dos processos de produção social do espaço, traduzido pela dinâmica da estrutura urbana e pelas condições locais, em quadros existenciais percebidos e valorizados. Essas sucessivas aproximações escalares têm uma grande importância para o planejamento das ações a serem pensadas para as regiões de estudo. Isso porque é na macroescala que se constroem mudanças significativas para a reestruturação urbana, porém, é na escala local que se dá o entendimento da estrutura de valores da sociedade, fornecendo a base e a instrumentação necessária para se tomar decisões coerentes, respeitando realidades e necessidades locais.

\section{ESTRATÉGIAS METODOLÓGICAS}

Estão sendo desenvolvidos estudos que visam monitorar e verificar a efetividade das intervenções em curso na região, observando como a população se insere na gestão das ações para o equacionamento dos conflitos socioambientais decorrentes da expansão da urbanização. Os estudos preveem procedimentos técnicos de análise da paisagem e pesquisa qualitativa. $\bigcirc$ objetivo é a compreensão das relações urbanas, suas potencialidades de articulação socioambiental, situações de pressão sobre mananciais e remanescentes vegetais, além de formas de participação social. São utilizados indicadores sociais, econômicos e ambientais para avaliação do uso e ocupação; a interpretação das informações provenientes da sobreposição de mapas temáticos, de acordo com a metodologia proposta por McHarg (1992) e Santos (2004); estudos cartográficos e de campo da integração de áreas livres como corredores ecológicos e de uso público em sua conexão com as tipologias urbanas; cartografia de atores e observação participante para verificar as relações de poder e os vínculos de interesses envolvidos nesse complexo sistema de gestão.

Efetuam-se observações de campo nas áreas de expansão urbana ao longo dos principais vetores identificados, dos espaços de uso público e de conservação ambiental, dos usos agrícolas e das diferentes tipologias urbanas. São considerados, nos campos realizados, diversos aspectos: as características da paisagem como articulação do tecido urbano com os espaços livres, tipos de uso e ocupação do solo, eixos de circulação, potencialidades para preservação de áreas verdes, entre outros. Para enriquecer o entendimento, utiliza-se coleta de dados qualitativos, por meio de entrevistas com gestores (representantes das Prefeituras Municipais e Secretarias envolvidas) e moradores, além do acompanhamento de reuniões dos conselhos consultivos e deliberativos incidentes na área (Comitê Gestor da APA Bororé-Colônia; Comitê de Bacia Hidrográfica do Alto Tietê - CBH-AT e Subcomitê de Bacia Hidrográfica do Cotia-Guarapiranga - SCBH-CG).

São realizadas análises verificando tipologias das manchas de expansão urbana e áreas de supressão de vegetação, utilizando como base o mapeamento de uso e ocu- 
pação do solo realizado pela Emplasa $(2005)$ na RMSP; e ISA $(2003,2006)$ nas bacias Billings e Guarapiranga. Os resultados são confrontados com as previsões disponíveis sobre crescimento da população a fim de identificar vetores e tipologias da expansão e seu impacto sobre áreas verdes e mananciais. Estão sendo feitas avaliações do uso e ocupação da bacia Guarapiranga no momento anterior à elaboração da legislação de mananciais vigente $(1989,1999,2003)$, por meio do mapeamento realizado pelo Instituto Socioambiental (ISA, 2006) e no momento posterior (2010, mapeamento a ser elaborado) a fim de avaliar as dinâmicas regionais em curso.

Entretanto, a aproximação de um sistema e sua efetiva possibilidade de gestão sobre o urbano depende da relação integrada que se estabeleça entre esses espaços, seus programas de uso e, principalmente, a compreensão e inclusão da população local. Para isso, é necessário discutir as transformações da paisagem na escala regional e conflitos decorrentes, correlacionando-as com as escalas locais no cotidiano da população, formas de apropriação dos espaços e acesso a recursos. Prevemos, com esse fim, a ampliação dos procedimentos de campo que se encontram em uma fase exploratória para processos mais dialógicos com a população, buscando a análise de elementos advindos dos protagonistas locais e gestores públicos. Nesse caso, são utilizadas a observação direta, observação participante, entrevistas com interlocutores-chave junto ao poder público e aos moradores identificados nas pesquisas.

\section{OCUPAÇÃO NAS ÁREAS DE MANANCIAIS E O SISTEMA DE ESPAÇOS LIVRES}

Os mapas de evolução da mancha urbana permitem observar que a região sul de São Paulo apresentou grande crescimento de sua área urbanizada no período de 1950 a 1974, estabelecendo firmemente o vetor de expansão sobre a área de mananciais até meados da década de 1970 (figura 1). Não tendo acesso às ofertas do mercado imobiliário, a população passou a se deslocar em direção às regiões de mananciais, por meio de processos informais de construção, apresentando, até o final da década de 1990, enorme aumento populacional e da área urbanizada. As favelas e os loteamentos irregulares foram a forma de enfrentar o déficit habitacional, ampliando a ocupação da cidade até praticamente circundar os reservatórios em questão. Meyer et al. (2004); Martins (2006), entre outros, sintetizaram alguns dos fatores a serem considerados no processo de metropolização e de expansão periférica em São Paulo, cujas consequências influenciaram sobremaneira a conformação atual das áreas no entorno dos reservatórios Billings e Guarapiranga.

As pesquisas do NEP nessa região e no setor noroeste da cidade identificam uma complexificação das atividades econômicas e funcionais, bem como de serviços no espaço intraurbano, em paralelo a investimentos públicos crescentes em espaços periféricos nos anos recentes, até então mais afastados da valorização imobiliária. Essas intervenções indicam um novo quadro institucional e econômico com consequente diversificação em curso na estruturação da metrópole. A decorrente valorização do preço da terra nessas 


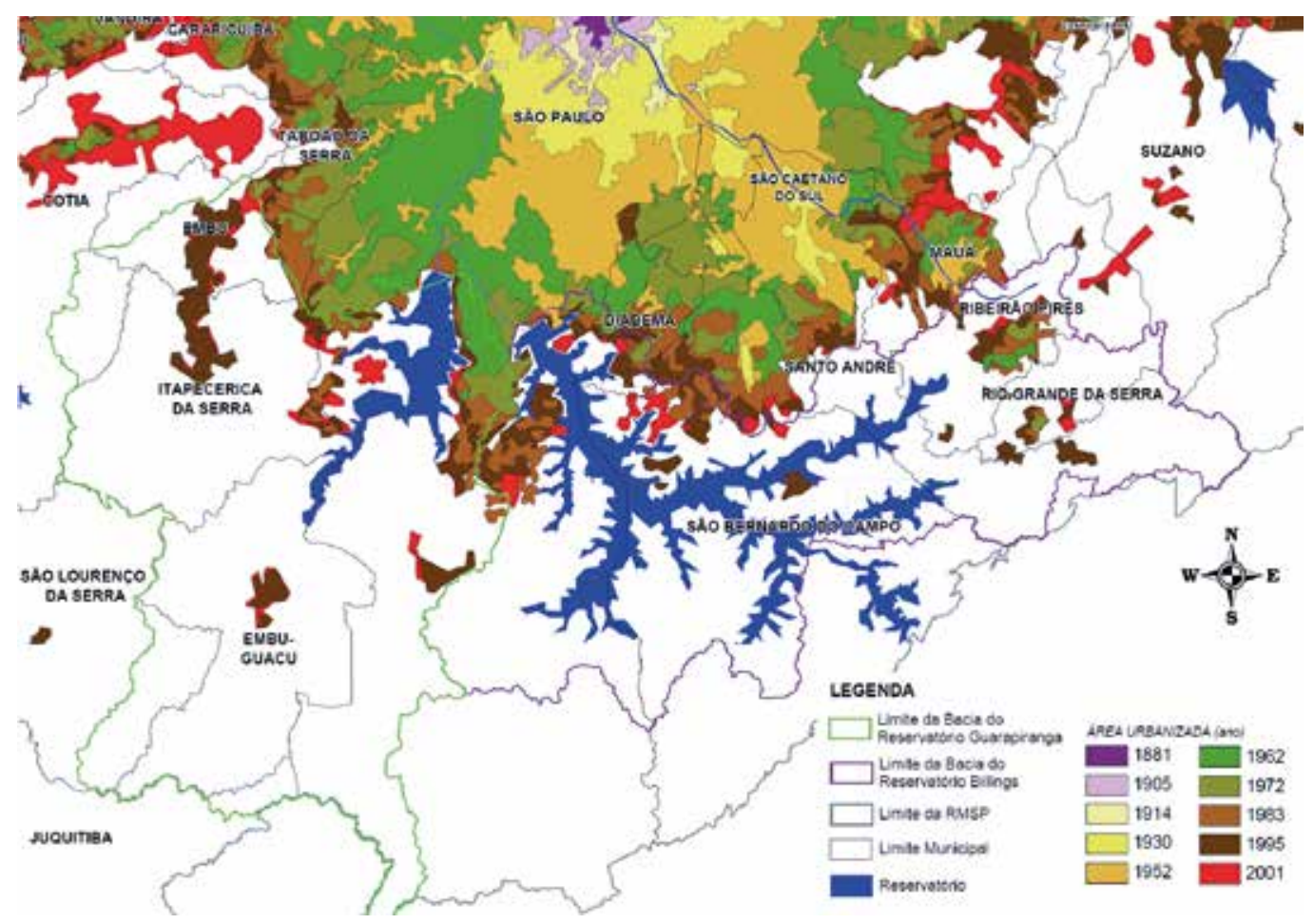

Figura 1 - Evolução da mancha urbana nas bacias Billings e Guarapiranga. Fonte: CESAD/FAUUSP. Elaboração: Priscila lkematsu - NEP/FAUUSP

áreas, nova acessibilidade e vantagens locacionais, torna a atrair investimentos públicos e privados, gera oportunidades de negócio, mas não enfrenta o quadro habitacional na metrópole. A exemplo de períodos anteriores, essas mudanças, desvinculadas de estudos de paisagem e da dinâmica socioambiental nas diversas escalas, além de uma série de elementos conjugados como a ausência de programas habitacionais efetivos, a carência e má qualidade dos serviços públicos de educação, cultura e saúde, têm conduzido ao agravamento das condições de vida de populações mais pobres. A expansão da mancha urbana em direção às periferias permanece associada, também, à forte especulação imobiliária informal, ou seja, a atuação de loteadores clandestinos decorrentes da segregação urbana, orquestrando de modo dramático processos de interesses particulares mais diversos com as ações e omissões do poder público.

Outro aspecto da dinâmica de expansão urbana, verificado pelas pesquisas do NEP, é o processo relevante de migração interna. A população, sem poder arcar com os custos resultantes da valorização dos terrenos que antes ocupavam (com a chegada de infraestrutura, melhorias urbanas, entre outros), migra para novas frentes de expansão em áreas de fragilidade ambiental. Ocorre que estudos realizados na zona norte e sul do município indicaram que muitas vezes a ocupação de novas fronteiras e áreas de fragilidade ambiental é promovida diretamente pela remoção de moradores por obras públicas e, menos perceptível, pelos impactos indiretos dessas obras no tempo maior do que o de sua execução. 
Os estudos conduzidos pelo NEP indicam, ainda, que ao menos entre os anos 2002 e 2009, nos municípios de Embu, Itapecerica e São Paulo, relativamente a anos anteriores, não houve expansão significativa da área urbanizada sobre novas frentes e, quando ocorreu, se deu de modo fragmentado e aparentemente em áreas já desmatadas ou inseridas na mancha urbana. Se confrontadas essas imagens com os dados de crescimento populacional, entretanto, verifica-se que a região ainda está em fase bastante intensa de adensamento da ocupação urbana já existente.

É importante destacar que a região está submetida a influências do Rodoanel Trecho Sul. Nossos estudos indicam que o Rodoanel não atuará como barreira à expansão da mancha urbana, na medida em que essa dinâmica decorre da continuidade do processo das décadas anteriores, a partir dos eixos de circulação viária já existentes e bastante sobrecarregados. Já ocorre uma tendência de adensamento urbano por todo um arco que se estende pelo M'Boi-Itapecerica-Embu-Guaçu-Parelheiros, ainda que atualmente muito disperso e pulverizado e menos intensa no município de São Paulo. Embora os acessos do Rodoanel estejam localizados apenas em Embu e no ABC, observa-se, mesmo no município de São Paulo, uma valorização imobiliária crescente desde sua implantação. Além disso, essa obra promove a segmentação do tecido urbano preexistente e, pelo menos nos casos observados em Itapecerica e Embu, pode contribuir para processos de segregação espacial da população de baixa renda.

A região, com grande potencialidade de valorização paisagística, tem seu potencial reduzido ou extinguido pela fragmentação de seus espaços públicos, distribuídos desigualmente pela região. A falta de uma visão de conjunto, com inexistência de um sistema estrutural de áreas livres públicas, decorre da configuração do tecido urbano - não exclusivo da zona sul de São Paulo. Resulta de adições sucessivas de loteamentos, em grande parte irregulares, e da deficiência do poder público em promover melhoria à qualidade de vida e desenvolvimento humano e ambiental, através de habitação, saneamento, saúde, educação, transporte, mas também através de áreas de conservação e lazer.

A cidade de São Paulo, como outros municípios da região metropolitana, não dispõe até hoje de um plano de sistema de espaços livres de uso e conservação ambiental. No entanto, em que pesem essas dificuldades históricas, alguns avanços institucionais na direção da constituição de um sistema de espaços públicos vão timidamente se realizando, infelizmente muitas vezes sem uma adequada atenção às implicações sociais dessas intervenções. Atualmente, o poder público vem respondendo a esse cenário a partir de diferentes programas, dos quais se destacam: Programa Parques Lineares, Programa Córrego Limpo, Operação Defesa das Águas - trabalho intersetorial de quatro secretarias estaduais e quatro municipais, retomar controle e reverter degradação dos mananciais, criação de Unidades de Conservação e Projeto 100 parques. Muitos dos projetos anunciados revelam antagonismos com a população local, remoções nem sempre necessárias e sem a devida atenção às implicações sociais que acarretam, bem como as obras apresentam-se inconclusas, entre outras questões que têm sido apontadas nos mais diversos fóruns de discussão da cidade. Tais projetos estão resultando na implementação de alguns parques na zona sul - Shangrilá, Jacques Costeau (atualmente 
com suas obras embargadas), Parque da Guarapiranga (estadual) e Parques Lineares como o Caulim e o Cocaia e as intervenções no Núcleo Cantinho do Céu. Nesse contexto, é importante citar a instalação dos parques decorrentes da Compensação Ambiental do Rodoanel Trecho Sul, protegendo as margens da rodovia, que também são objeto de estudo pelo NEP.

Como pode ser observado na figura 2, a região é caracterizada por uma área de transição entre o contínuo urbanizado e áreas de matas, chácaras, agricultura e outros usos. As áreas com presença de fragmentos vegetacionais permitem ainda constituir corredores e trampolins ecológicos ao sul do Rodoanel, contribuindo para a necessária permeabilidade do solo e qualidade dos recursos hídricos. No entanto, os parques decorrentes da compensação ambiental em implantação estão inseridos em meio a uma dinâmica urbana muito intensa e com marcada ausência do Estado. Entendemos que essa condição urbana deva ser assumida positivamente na formulação dos seus programas de uso, aliando a função de conservação a um papel social atento às necessidades dos moradores de seu entorno. No mesmo sentido, entendemos que sua gestão deva propor programas articulados com outros equipamentos e políticas urbanas em seu entorno.

Na medida em que se consolida o tecido urbano, os impactos nos recursos naturais eliminam gradualmente sua funcionalidade ecológica e deixam, quando deixam, poucas opções para a criação de espaços públicos de lazer e de conservação ambiental. Nesse sentido, os parques decorrentes da compensação ambiental, nessa fronteira

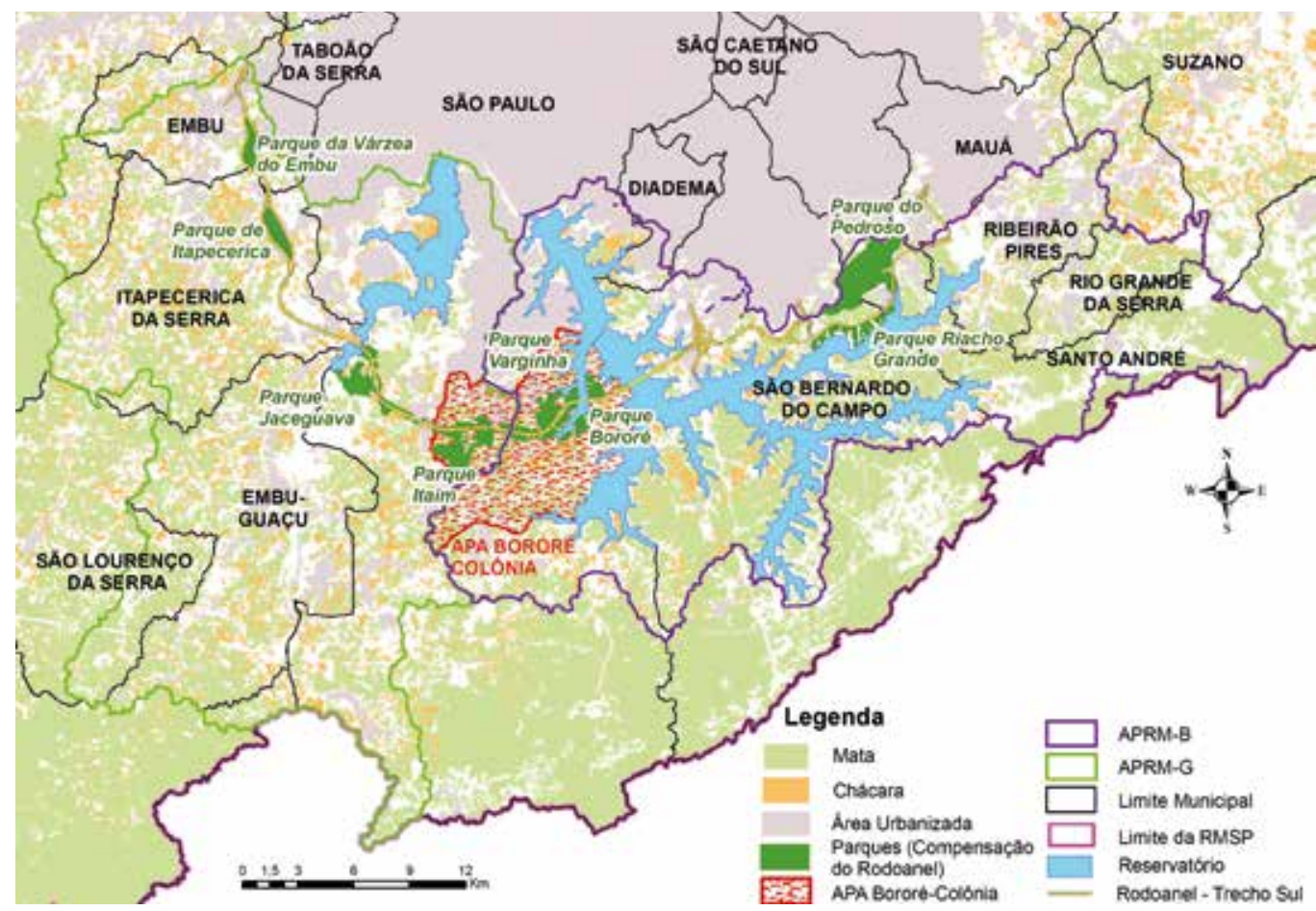

Figura 2 - Trecho Sul do Rodoanel, parques de compensação e mananciais. Fonte: DERSA (2009); EMPLASA (2005). Elaboração: Priscila Ikematsu NEP-FAUUSP. 
entre o contínuo urbanizado e áreas ainda parcialmente ocupadas, apresentam um potencial estratégico forte, mas insuficientes em si mesmos para salvaguardar uma função ambiental, se os considerarmos apenas no interior de seus perímetros. Devem-se observar limites à funcionalidade ecológica desses parques, que são dados por sua forma, extremamente fragmentada, o que vem a ampliar o "efeito de borda", por suas dimensões reduzidas, pela crescente pressão urbana no entorno, pela vegetação que abrigam bastante alterada, além de deixar fora de seus limites nascentes próximas. Isto é, sua eficácia, em termos de conservação biológica, só virá a existir se houverem políticas e ações públicas consorciadas que consigam atuar em um contexto mais amplo da paisagem.

Vale ressaltar que os parques do Embu e de Itapecerica, por proposição dessas prefeituras, não são unidades de conservação como os demais parques, mas sim Parques Urbanos, voltados a suprir uma grande carência por espaços verdes públicos nesses dois municípios. A configuração de paisagem em Embu e Itapecerica sugere, segundo o entendimento da nossa equipe, a concepção dos parques nesses municípios como um elemento central e articulador de gestão urbana. No entanto, em ambos é perceptível que o Rodoanel, e possivelmente os parques, agravem a segregação dos setores urbanos de baixa renda. Em Itapecerica, uma importante conexão apontada pelas equipes de uso do Plano de Manejo do parque com o Jardim Cinira foi ignorada nos entendimentos da Prefeitura e da DERSA, o que compromete consideravelmente a potencialidade de integração social, promovendo uma área de convívio e lazer desconectada da comunidade que a usufruía antes das obras do Rodoanel.

Ao norte do Rodoanel, no município de São Paulo (como a leste em Itapecerica e Embu), observa-se a ocupação mais consolidada, com notável adensamento na ocupação do solo e populacional, tornando extremamente custosas e problemáticas, do ponto de vista social, as intervenções reparadoras de situações críticas. Em relação ao sistema de espaços livres e de lazer, considerada, sobretudo, a região ao norte do Rodoanel, a situação é critica, uma vez que o intenso processo de urbanização não vem acompanhado da implantação de áreas e equipamentos públicos. $\bigcirc$ que se observa atualmente é a implantação de alguns parques, como o Parque da Guarapiranga, o Caulim e o Cocaia, em área de interesse do Plano de Manejo dos Parques da compensação ambiental do Rodoanel. Esses parques, no entanto, são insuficientes para a crescente demanda na região e sua localização também não favorece, em vários casos, uma articulação funcional com os parques decorrentes da compensação ambiental. Nesse sentido, é de suma importância pensar o Parque do Itaim juntamente com o Parque Linear Caulim, em implantação pela municipalidade, bem como dos cursos d'água que o atravessam, mas que não estão inteiramente compreendidos em seu perímetro (e sujeitos a pressões por urbanização), o que tem consequências para suas finalidades de conservação e uso em área de mananciais.

No Parque Itaim há expansão de ocupações de baixa renda muito próximas às suas fronteiras, como no bairro Jardim São Norberto e nas expansões no sul dos seus limites, que em alguns pontos já ocorrem lindeiras ao parque. A dinâmica observada em campo 
indica que a ocupação dessas áreas está em curso, de modo que as pressões podem se intensificar a curto prazo, não só com invasões de seu perímetro, mas com o uso inadvertido, ou sem orientação, de seus recursos pela população moradora no seu entorno.

Por sua inserção peculiar em contextos de pressão urbana, pelos recursos ainda existentes em infraestrutura edificada pelo potencial paisagístico e sua acessibilidade, a proximidade com núcleos urbanos pode se tornar um importante recurso na caracterização da função e do papel social desses parques, definindo sua contribuição em um possível sistema de áreas de conservação e uso público nessa região. Se, por um lado, esses processos podem representar riscos para a integridade dos recursos naturais do parque e sua conectividade na paisagem, por outro lado, como temos insistido, poderá se constituir em oportunidade, através de um programa social articulado e de longo prazo, para definir o papel que os parques poderão vir a ter na região. Destaca-se, ainda, a importância do Parque Itaim como unidade de conservação dentro do contexto urbano, apesar dos demais também o serem. O Itaim, devido a sua relação tão próxima com o entorno urbanizado, a proximidade com vias estruturais e transporte público, a proximidade com importantes equipamentos públicos e com o centro comercial de Parelheiros, poderá cumprir um papel inovador como unidade de conservação e promotor da integração social'.

Já no Parque Varginha, o relatório diagnóstico da APA Bororé-Colônia (SÃO PAULO, 2004) indica uma pressão crescente na porção norte do parque. Trata-se de uma ocupação irregular precária, com uma maior carência, em relação aos outros parques, de equipamentos e organização sociais, se considerarmos que não existe nenhuma representação no Conselho Gestor da APA Bororé-Colônia ou alguma Associação de Bairro cadastrada. Dentro do parque foram encontradas diversas edificações e espaços com potencial de contemplação, configurando um grande potencial para o uso turístico e lazer. Apresenta, ainda, áreas verdes e propriedades agrícolas em seu entorno, além de uma grande extensão ao sul margeada pela represa. Como o Itaim, também poderá ser direcionado para um importante diálogo e contribuição à população do entorno.

Destaca-se, finalmente, a urgência de um programa de fiscalização e monitoramento nesses parques. A depredação dos imóveis tem se intensificado e compromete a integridade desse patrimônio público, sobretudo no Parque do ltaim, como já ocorreu também no Parque do Embu. Isso tem dois efeitos graves: o aumento dos custos de implementação e o comprometimento de importante patrimônio edificado, favorecendo justificativas pela demolição de edificações ainda há pouco tempo em bom estado de conservação, que reduzem o potencial de uso e limitam imensamente as potencialidades desses parques.

\section{A QUESTÃO URBANA E O QUADRO INSTITUCIONAL}

A análise desse quadro socioambiental na zona sul indica que tem continuidade o comprometimento acelerado das funções ecológicas e de serviços ambientais na região, 
porém uma visão estritamente preservacionista não sustentará a potencialidade e a complexidade para a gestão pública nesse contexto de imensas necessidades sociais. As primeiras tentativas de obstar a degradação das áreas de manancial ocorreram na década de 1970, com a conclusão do Plano Metropolitano de Desenvolvimento Integrado - PMDI. Nessa década foram formuladas as Legislações de Proteção de Mananciais (Leis Estaduais n. 898/75, 1.172/76 e Decreto n. 9.714/77), que visavam compatibilizar as ações de uso da terra com a proteção dos mananciais utilizados para o abastecimento público. Naquele momento optou-se por restringir a expansão urbana na direção dos mananciais (vetor sul), liberando-a na direção leste-oeste, conforme preconizado pelo PMDI.

Os objetivos propostos, contudo, não foram concretizados, tendo, inclusive, efeitos contrários ao que se propunha (SOCRATES et al., 1985; MARCONDES, 1999; ISA, 2006; MARTINS, 2006; ISA, 2008). Esses estudos, geralmente, entendem que as dificuldades decorreram do caráter restritivo da Lei e de seu inflexível arcabouço normativo, com consequente redução do valor daquelas terras. A legislação e a ação pública não ponderaram as dinâmicas urbanas e as realidades e condições de vida da população de baixa renda, que seguiam um padrão diferente daquela proposta pela Lei, tornando-a ineficaz para lidar com a ilegalidade das ocupações e a concentração da população nessas regiões.

A urgência de revisão da legislação supracitada resultou na promulgação da Lei n. 9.866/97, destinada a proteger e recuperar os mananciais de interesse estratégico do Estado de São Paulo. Essa Lei constitui-se como um instrumento de planejamento ambiental, baseado no ordenamento territorial, considerando a gestão descentralizada, participativa e integrada e adotando o conceito de bacia hidrográfica como unidade de planejamento e gestão ${ }^{2}$. Prevê a elaboração de leis específicas para a definição de Áreas de Proteção e Recuperação de Mananciais (APRMs), a serem aprovadas no âmbito desse novo modelo de ordenamento e planejamento. A Lei n. 12.233/06 que define a Área de Proteção e Recuperação dos Mananciais da Bacia Hidrográfica do Guarapiranga (APRM-G) e a Lei n. 13.579/09 - que define a Área de Proteção e Recuperação dos Mananciais da Bacia Hidrográfica do Reservatório Billings (APRM-B) foram as primeiras aprovadas para esse fim, ambas com a proposta de integração de políticas regionais, setoriais e municipais. $\bigcirc$ mapeamento, das áreas de intervenção nas APRM-G e APRM-B, está apresentado na figura 3 e ilustra a proposta de preservação, recuperação e conservação dos mananciais Billings e Guarapiranga.

A compreensão da efetividade da proposta de proteção preconizada pela Lei $n$. 9.866/97 e respectivas leis específicas é de suma importância na atual conjuntura de degradação que caracteriza as áreas de mananciais da RMSP. A identificação dos conflitos, obstáculos e desafios no planejamento e gestão das APRMs pode auxiliar sobremaneira na identificação de entraves, a fim de ponderar a possibilidade de aperfeiçoar os instrumentos propostos. Apesar de representar avanços notáveis em relação às leis anteriores na incorporação de instrumentos de gestão, do ponto de vista da governança, deve ser considerado que a atual Lei de proteção aos mananciais se 


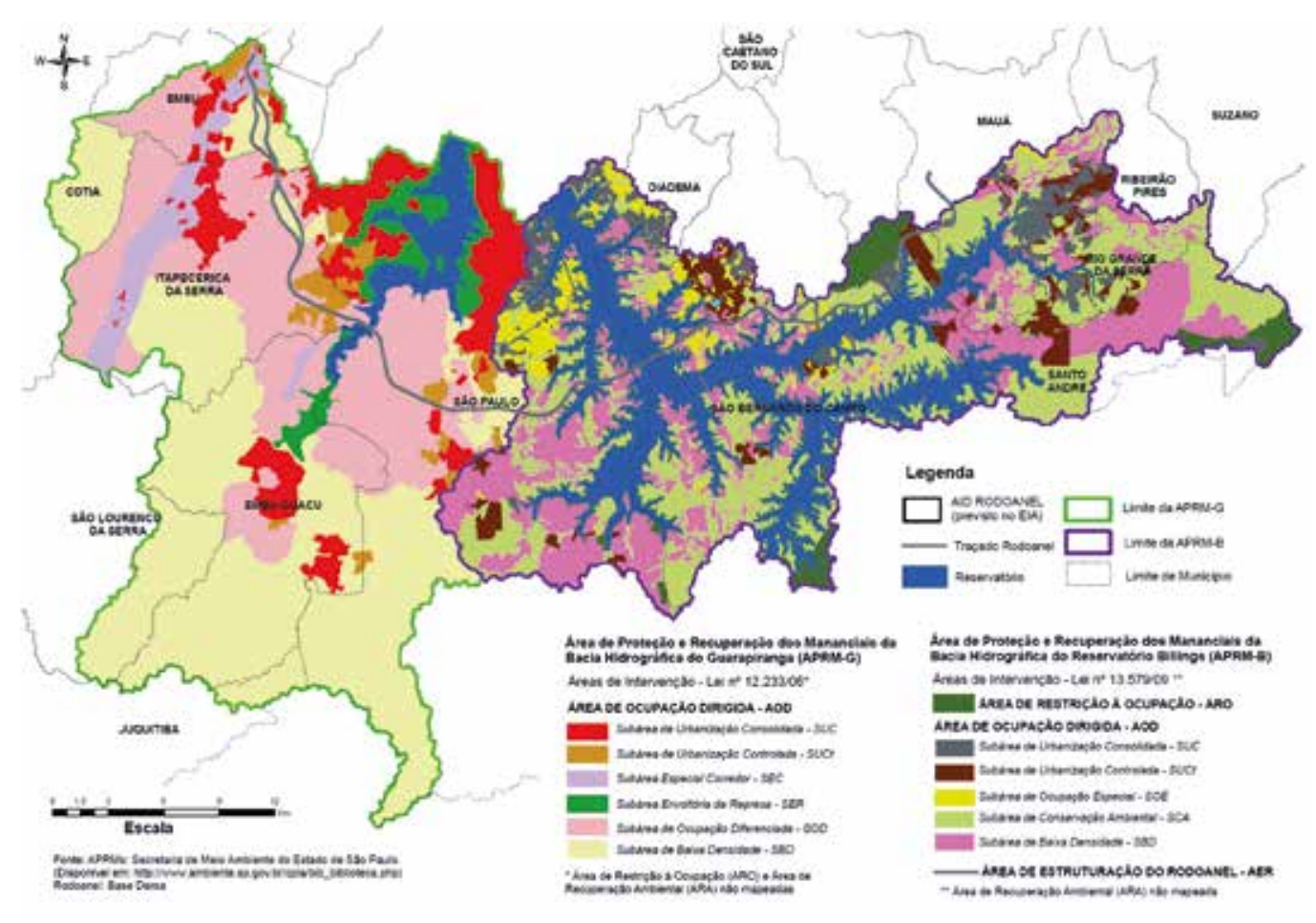

Figura 3 - Áreas de proteção e recuperação dos mananciais da Região Metropolitana de São Paulo, criadas por meio de Lei específica: APRM-G e APRM-B e respectivas áreas de intervenção.

Fonte: SÃO PAULO (2006); SÃO PAULO (2009). Elaboração: Priscila Ikematsu/ NEP-FAUUSP

insere num quadro marcado por inúmeros conflitos relacionados ao uso da água. A existência de interesses divergentes implica na necessidade de uma constante política de negociação dentro da relação paradoxal entre a proteção das águas e as formas de ocupação do território.

Outro aspecto importante no uso e ocupação de áreas de mananciais, pouco abordado nas discussões acerca das dinâmicas urbanas, é a questão dos usos rurais ainda existentes na metrópole paulista. A porção sul do município de São Paulo, além de uma área urbanizada extensa e concentrada, apresenta, ainda, características de ruralidade, pois sua paisagem é composta de propriedades agrícolas conjugadas a áreas verdes ricas em biodiversidade, indicando o potencial da região para a conservação dos recursos hídricos e contenção da expansão urbana irregular. Os espaços rurais integrados a sistemas urbanos passam a ser delimitados cada vez menos como áreas apenas de produção agrícola, sendo incorporado também a sua relevância na preservação e proteção de recursos naturais (ABRAMOVAY, 2000).

$\mathrm{Na}$ tentativa de proteger o caráter rural da localidade foram criadas, pelo município de São Paulo, duas Unidades de Conservação (UC) de uso sustentável previstas no Sistema Nacional de Unidades de Conservação - SNUC: as Áreas de Proteção Ambiental (APA) Capivari-Monos (Lei Municipal n. 13.706/04) e Bororé-Colônia (Lei Municipal n. 14.162/06). O estabelecimento dessas APAs vem ampliando o contato 
entre as comunidades locais por meio das reuniões do Conselho Gestor, estabelecendo mecanismos que ainda são insuficientes de diálogo da população com a gestão pública, mas já permitindo levantar problemas locais e soluções conjuntas. O NEP desenvolve estudos na APA Bororé-Colônia (figura 2). Constituída por uma dimensão territorial de $90 \mathrm{~km}^{2}$, caracterizada pelo contraste entre o tecido urbano e a paisagem rural, essa APA é ocupada por aproximadamente 40 mil habitantes que, em sua maioria, vivem de atividades agrícolas. Sua localização é estratégica porque está situada no limite do adensamento populacional paulistano, sendo uma potencial barreira de contenção da expansão urbana. Está delimitada, em sua maioria, na bacia hidrográfica da Represa Billings, coincidente com a APRM-B, inclusive em sua margem, porém também abrange a região de interflúvio e uma pequena porção da bacia hidrográfica da Represa Guarapiranga, cujos limites são os mesmos da APRM-G.

Os produtores locais passam por um processo de adequação às normas de uso sustentável de acordo com uma série de leis estaduais e municipais no que concerne à conversão de sistemas de produção agrícolas convencionais para sistemas agroecológicos. Esse processo de conversão agroecológico é regulamentado pela Resolução Conjunta-08 entre SAA (Secretaria Estadual da Agricultura e Abastecimento) / SMA (Secretaria Estadual do Meio Ambiente), de 21 de dezembro de 2009, sendo estabelecida a determinação e o incentivo a práticas de agricultura sustentável nas APRMs do Alto do Tietê. Como consequência, os produtores locais terão quatro anos para praticar o manejo sustentável do solo. Esta Resolução Conjunta prevê que o poder público deve dar apoio ao processo de conversão dos sistemas de produção, principalmente à agricultura familiar, que constitui cerca de $80 \%$ dos agricultores na região. Verifica-se que poucos produtores locais efetivamente buscaram o processo de conversão para orgânicos anteriormente a essa série de leis e programas ambientais, existindo apenas ações pulverizadas e não organizadas que pouco foram fortalecidas. Contudo, o processo de conversão para uma produção agrícola orgânica, baseada em ajustes tecnológicos de baixo impacto ambiental e fortalecimento da rede social local, promove a agricultura familiar como uma potencial forma de conservação para prestação de serviços ambientais no território periurbano (CARVALHO, 2006).

Todo esse aparato normativo e institucional, que incide sobre as regiões em estudo, ainda é relativamente recente e não logra articular todas as instâncias públicas envolvidas. Além das instâncias dos Comitês de Bacia Hidrográfica e Comitês Gestores, cujas ações estão sendo acompanhadas, verifica-se que, gradualmente, há a necessidade de descentralizar determinadas funções, como ocorre com a criação das Subprefeituras (Lei n. 13.399/02), sem assegurar uma forma democrática de gestão. Isso vem ocorrendo em diversas outras instâncias no município de São Paulo, por exemplo, com o Departamento de Gestão Descentralizada (DGD), ou ampliação do número de Conselhos (e Conselheiros), como com o Cades - Conselho Municipal do Meio Ambiente e Desenvolvimento Sustentável (Lei n. 11.426/93), que em sua versão local não é deliberativo, - Conselho Regional de Meio Ambiente, Desenvolvimento Sustentável e Cultura de Paz das Subprefeituras (Lei n. 14.887/09). 
Em tese, essas e outras estruturas existentes poderiam favorecer potencialmente um papel articulador mais próximo à população local, diferentemente de práticas públicas mais comuns como coleta de dados estatísticos e análise em gabinete distantes da diversidade da realidade local. No entanto, apesar de alguns esforços de descentralização, como a criação de conselhos com representantes da sociedade civil, ainda estamos muito longe de uma prática participativa na gestão do território. Essa multiplicidade de instrumentos de políticas públicas existentes e de núcleos diversos de decisão leva a uma imensa multiplicação das instâncias colegiadas que são desarticuladas entre si, pela inexistência de um planejamento de integração entre as diversas ações locais. Também é fundamental analisar a sobrecarga de atividades cotidianas que dificultam a participação dos moradores da região nestas múltiplas instâncias, pois o deslocamento para os postos de trabalho e residência muitas vezes tem a mesma duração da jornada de trabalho.

Outra característica dessa complexificação da gestão pública pode ser notada nas formas de acesso e distribuição de recursos, que a exemplo do que ocorre na área da cultura e da saúde, na gestão ambiental também são acessadas pelo chamado terceiro setor no provimento de questões sociais através da captação desses recursos, como se dá, por exemplo, pelos editais do Fundo Especial do Meio Ambiente (FEMA). Essa nova realidade administrativa, comum aos diversos níveis de governo, corresponde à necessidade de ampliação das interfaces político-administrativas (e partidárias, portanto) com a população e das formas de distribuição de recursos que adquire feições mais capilarizadas.

Os diversos estudos realizados pelo NEP indicam uma recorrente oposição à participação popular no planejamento da paisagem e na sua relação com as ações públicas em curso, apesar do poder público aparentar uma vontade na crescente participação popular. A partir dos estudos realizados ficou clara a falta de adequabilidade de diversos projetos à situação real, resultando em planos, por vezes, formalmente bem elaborados e estruturados, mas não aplicáveis à situação local. Essas observações justificam a necessidade de discutir como a participação popular poderia ser estimulada e potencializada nas ações de planejamento. Entende-se, portanto, que necessitamos superar as políticas públicas baseadas apenas em legislação de controle de uso do solo, e em comando e controle, pois são necessários ações e investimentos voltados para educação e capacitação dialógica da população, favorecendo a cidadania e o pertencimento.

\section{CONCLUSÃO}

Os estudos realizados na área de mananciais dos reservatórios Billings e Guarapiranga reforçam a urgência de ações voltadas à melhoria da qualidade socioambiental e urbana dessa região. É de suma importância a fiscalização e o monitoramento das dinâmicas no âmbito da complexidade da metrópole paulista, e que se inclua também a população em processos educativos e participantes em torno dessa questão, sob o risco de comprometimento de importantes trechos nessas áreas. 
Os trabalhos indicaram que o Rodoanel pode operar como uma barreira que reforça a exclusão social por um lado, e por outro pode favorecer processos mais especulativos ligados a loteamentos fechados. Estes tendem a entrar em conflito com novas plantas industriais e do setor terciário, que por sua vez não são pensados em uma política que considere a criação de oportunidades de emprego para a população já residente nessas regiões. Por outro lado, essas dinâmicas novas, que já se notam alterando a estrutura do uso do solo na região, tendem a levar a uma sobrecarga do viário de uma importante rede de circulação, que conecta fluxos entre os diversos municípios desse setor da metrópole. Nesse sentido, parece-nos bastante grave a não consideração de um sistema de circulação que reconecte o tecido urbano, gerando simultaneamente acesso a oportunidades de lazer e trabalho para as populações de baixa classe de renda, residentes nessas áreas mais sensíveis do ponto de vista social e ambiental.

Há também carência de áreas de uso público, como parques e praças, e de uma política de conservação ambiental consistente e continuada, embora haja importantes áreas remanescentes ou com potencial para criação de um sistema de espaços livres, e os Planos Diretores recentes tendam a incorporar essa visão nas diretrizes de uso do solo no município.

Esses estudos em curso irão se direcionar, em uma próxima etapa, a uma abordagem priorizando a observação direta de situações apresentadas na realidade local de acordo com as opções metodológicas do NEP. A interação entre o pesquisador e os atores locais, de forma dialógica, deverá orientar o detalhamento da investigação. Esses procedimentos, ao lado dos estudos em curso de estrutura urbana, políticas públicas e sistemas da paisagem, visam uma aproximação da percepção do espaço vivido, relacionando a estrutura urbana e ambiental na escala regional e sua correspondência na escala local e no cotidiano da população. No entanto, a complexidade e a escala espacial dos fenômenos colocam problemas adicionais à pesquisa, sendo, no momento, necessária a ampliação da equipe para trabalhos colaborativos com grupos locais. Essa frente de trabalhos das pesquisas em curso, em vias de se iniciar (foram realizados até o momento basicamente campos exploratórios), poderá trazer nova compreensão dos processos acima descritos, bem como iluminar e problematizar aspectos que contribuam para a análise das implicações das políiticas públicas e dos processos de construção do urbano, de seus contextos políticos, e esclarecer as atuais condições para uma efetiva participação da população no planejamento e gestão das áreas de mananciais intensamente urbanizados.

\section{Notas}

1 O Parque do Itaim também está sendo discutido no âmbito da disciplina de graduação da FAUUSP AUP 667 - Análise Paisagístico-Ambiental, tendo como monitores os pesquisadores Gabriella Radoll, Simone Miketen e Henqrique Pozo. O objetivo da disciplina é elaborar, no contexto do Plano de Manejo da APA do Bororé-Colônia, trabalhando na forma de um escritório de projeto, envolvendo alunos de graduação, de pós-graduação, colaboradores e docentes, o diagnóstico e estratégias de implantação do Parque Itaim, que serão encaminhadas como contribuição aos gestores públicos, técnicos e entidades envolvidas. 
2 Princípios estabelecidos na Lei Estadual n. 7.663 de 30 de dezembro de 1991, que indica as normas de orientação à Política Estadual de Recursos Hídricos, bem como ao Sistema Integrado de Gerenciamento de Recursos Hídricos (SIGRH).

\section{Bibliografia}

ABRAMOVAY, R.. Funções e medidas da ruralidade no desenvolvimento contemporâneo. Rio de Janeiro: IPEA, 2000.

CARVALHO, Y.M.C. et al. Agricultura: Serviço ambiental para a bacia do Alto Tietê-Cabeceiras. São Paulo em perspectiva. v. 20, n. 2. São Paulo: Fundação Seade, 2006. p. 118-135. Disponível em: <http://www.seade.gov. br>; <http://www.scielo.br>.

DERSA. Informações vetorizadas dos Planos de Manejo dos Parques de Compensação Ambiental. DERSA, 2009. Cd-rom.

EMPLASA - EMPRESA PAULISTA DE PLANEJAMENTO METROPOLITANO S.A. Uso e ocupação do solo da região metropolitana de São Paulo (ano: 2002). Escala 1: 25.000. EMPLASA, 2005.

IKEMATSU, P.; SANDEVILLE JR., E. Obstáculos, conflitos e desafios no planejamento e gestão da Área de Proteção e Recuperação dos Mananciais da Bacia Hidrográfica do Guarapiranga (APRM-G). III Encontro Internacional da Governança da Água: Desafios Interdisciplinares. Anais... PROCAM-USP. São Paulo, 2011. Cd-Rom.INSTITUTO SOCIOAMBIENTAL - ISA. Seminário Billings 2002. Avaliação e identificação de áreas prioritárias para conservação, recuperação e uso sustentável da Bacia Hidrográfica Billings. São Paulo: Instituto Socioambiental, 2003. (Formato shapefile, CD-rom.)

Guarapiranga 2005: Como e por que São Paulo está perdendo este manancial. Resultados do diagnóstico socioambiental participativo da bacia hidrográfica da Guarapiranga. São Paulo: Instituto Socioambiental, 2006. (Formato Shapefile, Cd-Rom.)

ISA, 2008.

Lei específica da Guarapiranga: Contribuições para sua compreensão e implementação. São Paulo:

MARCONDES, M.J.A.. Cidade e natureza: Proteção dos mananciais e exclusão social. São Paulo: Studio Nobel, 1999. 238p. (Coleção Cidade Aberta.)

MARTINS, M. L. R. R.. Moradia e mananciais. São Paulo: FAUUSP/Fapesp, 2006. 206p.

MCHARG, I. L.. Design with nature. Nova York: John Wiley, 1992.

MEYER, R.M.P.; GROSTEIN, M.D.; BIDERMAN, C.. São Paulo metrópole. São Paulo: Edusp/Imprensa Oficial, 2004.

SANDEVILLE JR., RADOLL, G. R.. Dinâmicas da paisagem: Espaço público, infraestrutura verde e participação social nas políticas públicas. Arq.Urb - Revista Eletrônica de Arquitetura e Urbanismo, v. 4, p. 55-79, 2010.

SANTOS, R.F.. Planejamento ambiental: Teoria e prática. São Paulo: Oficina de Textos, 2004.

SÃO PAULO (Estado). Lei n. 12.233, de 16 de Janeiro de 2006. Define a Área de Proteção e Recuperação dos Mananciais da Bacia Hidrográfica do Guarapiranga, e dá outras providências correlatas. Diário Oficial do Estado, São Paulo, 17 jan. 2006. Seção I, p. 1. Disponível em: <http://www.socioambiental.org/nsa/doc/12233.pdf>. Acesso em jul. 2011.

. Lei n. 13.579, de 13 de Julho de 2009. Define a Área de Proteção e Recuperação dos Mananciais da Bacia Hidrográfica do Guarapiranga, e dá outras providências correlatas. Diário Oficial do Estado, Poder Executivo, São Paulo, 14 jul. 2009. p. 1-7. Disponível em: <http://www.al.sp.gov.br/legislacao/norma.do?id=156946>. Acesso em: jul. 2011.

Secretaria Municipal do Verde e Meio Ambiente. APA Bororé-Colônia: diagnóstico socioambiental preliminar. São Paulo, 2004

SÓCRATES, J.R., GROSTEIN, M.D.; TANAKA, M.M.S.. A cidade invade as águas: Qual a questão dos mananciais? São Paulo: FAUUSP, 1985. 296p. 
